\title{
Questes
}

\section{La règle du jeu : éléments bibliographiques}

\section{Amandine Mussou et Laëtitia Tabard}

\section{(2) OpenEdition}

\section{Journals}

Édition électronique

URL : http://journals.openedition.org/questes/675

DOI : 10.4000/questes.675

ISSN : 2109-9472

\section{Éditeur}

Les Amis de Questes

\section{Édition imprimée}

Date de publication : 15 février 2010

Pagination : 107-112

ISSN : 2102-7188

\section{Référence électronique}

Amandine Mussou et Laëtitia Tabard, «La règle du jeu : éléments bibliographiques », Questes [En ligne], 18| 2010, mis en ligne le 01 janvier 2014, consulté le 15 septembre 2020. URL : http:// journals.openedition.org/questes/675 


\section{Éléments bibliographiques}

\section{Approches théoriques}

BENVENISTE, Émile, « Le jeu comme structure », Deucalion, cahiers de philosophie, 11 (1947), Paris, Éditions de la Revue Fontaine, p. 159-167.

Berchtold, Jacques, Lucken, Christopher, SchottKe, Stefan (dir.), Désordre du jeu Poétiques ludiques, Genève, Droz, "Recherches et Rencontres » (Publications de la Faculté des Lettres de l'Université de Genève), vol. 6, 1994.

CAILloIS, Roger, « Structure et classification des jeux », Diogène, XII (1955), p. 72-88.

CAILloIS, Roger, « Unité du jeu, diversité des jeux », Diogène, XIX (1957), p. 117-144.

CAILlois, Roger, Les Jeux et les hommes. Le masque et le vertige, Paris, Gallimard, 1958 ( $1^{\text {ère }}$ édition), 1967 (édition revue et commentée).

Calvet, Louis-Jean, Les Jeux de la société, Paris, Payot, 1978.

Duvignaud, Jean, Le Jeu du jeu, Paris, Balland, 1980.

EHRMANN, Jacques, «Homo ludens revisited» (translated by Cathy and Phil LEWIS), Yale French Studies, XLI (1968), Game, Play, Literature, p. 31-57.

FINK, Eugen, Le Jeu comme symbole du monde, Paris, Les Éditions de Minuit, 1966 ( $1^{\text {ère }}$ édition en allemand en 1966).

Gusdorf, Georges, «L'esprit des jeux », in Roger CAILlois (dir.), Jeux et sports, Encyclopédie de la Pléiade, Paris, 1967, p. 1157-1180.

Henriot, Jacques, Le Jeu, Paris, PUF, « Le Philosophe », 1969.

Henriot, Jacques, Sous couleur de jouer. La métaphore ludique, Paris, José Corti, 1989.

Huizinga, Johan, Homo Ludens, essai sur la fonction sociale du jeu, traduit par Cécile SERESIA, Paris, Gallimard, 1951 ( 1 ère édition en 1938).

Lhote, Jean-Marie, Le Symbolisme des jeux, Paris, Berg-Bélibaste, 1976.

PICARD, Michel, La Lecture comme jeu. Essai sur la littérature, Paris, Les Éditions de Minuit, « Critique », 1986.

\section{Histoire des jeux}

Aries, Philippe, Margolin, Jean-Claude (dir.), Les Jeux à la Renaissance. Actes du XXIII colloque international d'études humanistes (juillet 1980), Paris, Vrin, 1982.

BEART, Charles, «Histoire des jeux », in Roger CAILlois (dir.), Jeux et sports, Encyclopédie de la Pléiade, Paris, 1967, p. 181-286

CARTER, John Marshall, Medieval Games. Sports and Recreations in Feudal Society, Westport, Greenwood Press, 1992.

Del Negro, Pietro, OrTalli, Gherardo (dir.), Il gioco e la guerra nel secondo millenio, Treviso, Éd. Fondazione Benetton studi ricerche, 2008. 
HeERs, Jacques, Fêtes, jeux et joutes dans les sociétés d'Occident à la fin du Moyen Âge, Montréal, Institut d'études médiévales/ Paris, Vrin, 1971.

JuSSERAND, Jean-Jacques, Les Sports et jeux d'exercice dans l'ancienne France, Paris, Champion, 1901/ Genève, Slatkine reprints, 1986.

MeHL, Jean-Michel, Les Jeux au royaume de France, du XIII au début du XVI siècle, Paris, Fayard, 1990.

MeHL, Jean-Michel (dir.), Jeux, sports et divertissements au Moyen Âge et à l'Âge classique, Paris, Éditions du Comité des Travaux Historiques et Scientifiques (CTHS), 1993.

Netchine, Ève (dir.), Jeux de princes, jeux de vilains. Exposition, Paris, Bibliothèque de l'Arsenal (2009), Paris, Seuil/BnF, 2009.

Voir également le site de l'exposition : http://expositions.bnf.fr/jeux/

Ortalli, Gherardo, «Tempo libero e Medioevo: tra pulsioni ludiche e schemi culturali », in Simonetta CAVACIOCCHI (dir.), Il tempo libero. Economia e società (Loisirs, Leisure, Tiempo libre, Freizeit), Secc. XIII-XVIII, Firenze, Le Monnier, Istituto internazionale di storia economica «F. Datini », Prato (Serie II: Atti delle settimane di studi e altri convegni, 26), 1995, p. 31-54.

RizzI, Alessandra, "Il gioco fra norma laica e proibizione religiosa : l'azione dei predicatori fra Tre e Quattrocento », in Gherardo ORTALLI (dir.), Gioco e giustizia nell'Italia di Comune, Roma, Viella, 1993, p. 149-182.

RizzI, Alessandra, «Le jeu dans les villes de l'Italie médiévale », Histoire urbaine, 1 (2000), p. 47-64.

VERDON, Jean, «Fêtes et divertissements en Occident durant le haut Moyen Âge », Journal of Mediaeval History, V (1979), p. 303-316.

Verdon, Jean, Les Loisirs au Moyen Âge, Paris, Tallandier, 1980.

Voir également le site de l'exposition «La règle du jeu : la tradition ludique dans le patrimoine écrit » s'étant déroulé du 18 septembre au 19 décembre 2005 dans la salle de lecture de la Réserve de la Bibliothèque Sainte-Geneviève : http://www-bsg.univparis1.fr/la reserve/expos/jeu/accueiljeu.htm

Pour une bibliographie plus complète, on peut se reporter à la revue Ludica. Annali di storia e civiltà del gioco, dirigée par Gherardo ORTALLI, qui publie des articles et recense les ouvrages consacrés à la question du jeu (depuis 1995).

Voir en particulier les dossiers "Materiali per un colloquio : Jeux, cultures et sociétés du Moyen Âge au XX $X^{\mathrm{e}}$ siècle », Ludica, 3 (1997), p. 103-176, " Il Gioco e la guerra nel secundo millennio ", Ludica, 10 (2004), p. 8-180, "Gioco e piccole communità », Ludica, 11 (2005), p. 89-152, et «Giocatori d'azzardo, imprenditori e burocrati di Stato », Ludica, 12 (2006), p. 36-137. 


\section{Jeux de société}

\section{Le jeu d'échecs : « jeu des rois et roi des jeux»}

Adams, Jenny, Power Play. The Literature and Politics of Chess in the Late Middle Ages, Philadelphia, University of Pennsylvania Press, "The Middle Ages Series », 2006.

Bellon-Meguelle, Hélène, «Mener joieuse vie : la partie d'échec dans Les Voux du paon de Jacques de Longuyon, (vv. 20682-2882)", in Olivier COLLET, Yasmina Foehr-Janssens, Sylviane Messerli (dir.), Ce est li fruis selonc la letre. Mélanges offerts à Charles Méla, Paris, Champion, 2002, p. 147-159.

BERChTOLD, Jacques, «L'Échiquier et la harpe. Parties d'échecs et registres ludiques dans la légende de Tristan chez Gottfried de Strasbourg et ses continuateurs ", Médiévales, 11 (1986), p. 31-48.

BERCHTOLD, Jacques, «L'échiquier absent. À propos d'une disparition signifiante dans le Conte $d u$ Graal de Chrétien de Troyes », in Jacques BERCHTOLD, Christopher LUCKen et Stefan SchotTKe (dir.), Désordre du jeu-Poétiques ludiques, Genève, Droz, «Recherches et Rencontres» (Publications de la Faculté des Lettres de l’Université de Genève), vol. 6, 1994, p. 97-124.

BlaKesleE, Merritt R., «Lo dous jeux sotils : la partie d'échecs amoureux dans la poésie des troubadours ", Cahiers de civilisation médiévale. $X^{e}-X I I^{e}$ siècles, Université de Poitiers, XXVIII (1985), p. 213-222.

Constable, Olivia Remie, "Chess and Courtly Culture in Medieval Castile: The Libro de ajedrez of Alfonso X, el sabio », Speculum, vol. 82 n² (avril 2007), p. 301347.

DeXtreit, Jacques, Engel, Norbert, Jeu d'échecs et sciences humaines, Paris, Payot, 1981.

Ferm, Olle, Honemann, Volker (dir.), Chess and Allegory in the Middle Ages, Stockholm, Sällskapet Runica et Mediaevalia, 2005.

Gally, Michèle, "Permanences échiquéennes ou le sens d'une métaphore transséculaire ", in Amandine Mussou et Sarah Troche (dir.), Le Jeu d'échecs comme représentation: univers clos ou reflet du monde?, Paris, Éditions rue d'Ulm, « Actes de la recherche à l'ENS », 2009, p. 51-63.

JONIN, Pierre, «La partie d'échecs dans l'épopée médiévale », in Mélanges de langue et littérature du Moyen Âge et de la Renaissance offerts à Jean Frappier, Genève, Droz, 1970, t.1, p. 483-497.

MeHL, Jean-Michel, Jeu d'échecs et éducation au XIII siècle. Recherches sur le « Liber de moribus " de Jacques de Cessoles, Thèse de $3^{\text {ème }}$ cycle, Université des sciences humaines de Strasbourg, 1975.

MeHL, Jean-Michel, «Le roi de l'échiquier», Revue d'histoire et de philosophie religieuse, tome LVIII (1978), Paris, Presses Universitaires de France, p. 145-161.

MeHL, Jean-Michel, «Le jeu d'échecs à la conquête du monde », L'Histoire, n71 (octobre 1984), p. 40-50. 
MuEller, Rainer A., « Il gioco degli scacchi come metafora della società tardomedievale », Ludica, 1 (1995), p. 114-125.

Mussou, Amandine, "La cité idéale selon Jacques de Cessoles : les échecs, instrument d'une propagande royale ", in Amandine Mussou et Sarah Troche (dir.), Le Jeu d'échecs comme représentation : univers clos ou reflet du monde?, Paris, Éditions rue d'Ulm, « Actes de la recherche à l'ENS », 2009, p. 25-36.

Murray, Harold James R., A History of Chess, Oxford, Clarendon Press, 1913.

Pastoureau, Michel, "L'arrivée du jeu d'échecs en occident», in Une histoire symbolique du Moyen Âge occidental, Paris, Seuil, 2004, p. 269-291.

Pastoureau, Michel, L'Échiquier de Charlemagne, un jeu pour ne pas jouer, Paris, Adam Biro, « Un sur un », 1990.

\section{Jeux à la cour, jeux de cour}

ANDRIEUX-REIX, Nelly, "Le vocabulaire du loisir en ancien français classique $\left(\mathrm{XII}^{\mathrm{e}}\right.$ $\mathrm{XIII}^{\mathrm{e}}$ siècles) : le deport et les deduiz », in Jean-Marie ANDRE, Jacqueline DANGEL, Paul DEMONT (dir.), Les Loisirs et l'héritage de la culture classique. Actes du XIII Congrès de l'Association Guillaume Budé (Dijon, 27-31 août 1993), Bruxelles, Latomus, Revue d'études latines, 1996, p. 477-486.

BADEL, Pierre-Yves, « Jouer aux rois et aux reines - jouer à tintin (d'Adam de la Halle à Charles d'Orléans) », in Claudio GALDERISI et Jean MAURICE (dir.), "Qui tant savoit d'engin et d'art. " Mélanges de philologie médiévale offerts à Gabriel Bianciotto, Poitiers, Université de Poitiers, Centre d'études supérieures de civilisation médiévale (Civilisation médiévale, 16), 2006, p. 253-262.

Ballestracci, Ducio, La Festa in armi. Giostre, tornei e giochi del Medioevo, Rome/Bari, Laterza, 2001.

BLANCHARD, Joël, «Le loisir du prince chez les chroniqueurs de la fin du Moyen Âge », in Jean-Marie ANDRE, Jacqueline DANGEL, Paul Demont (dir.), Les Loisirs et l'héritage de la culture classique. Actes du XIII Congrès de l'Association Guillaume Budé (Dijon, 27-31 août 1993), Bruxelles, Latomus, Revue d'études latines, 1996, p. 470-476.

Bozzolo, Carla, La Cour amoureuse dite de Charles VI, Paris, Le Léopard d'or, 1982.

Cerquiglini-Toulet, Jacqueline, «Le loisir et le concept de "récréation" à la fin du Moyen Âge ", in Jean-Marie Andre, Jacqueline Dangel, Paul Demont (dir.), Les Loisirs et l'héritage de la culture classique. Actes du XIII Congrès de l'Association Guillaume Budé (Dijon, 27-31 août 1993), Bruxelles, Latomus, Revue d'études latines, 1996, p. 503-512.

Felberg-LeVITt, Margaret, « Jouer aux demandes d'amour », Le Moyen Français, 38 (1997), p. 93-124.

FINOLI, Anna Maria, " Un gioco di società, le roi qui ne ment e le demandes en amour nel Chevalier errant di Tommaso III di Saluzzo », Studi Francesi, 79 (1983), p. 257264.

Gally, Michèle, Parler d'amour au puy d'Arras. Lyrique en jeu, Orléans, Paradigme, « Medievalia », 2004. 
Guichard-Tesson, Françoise, "Jeux de l'amour et jeux du langage », Le Moyen Français, 38 (1997), p. 21-44.

GREEN, Richard F., «Le Roi qui ne ment and Aristocratic Courtship », in Keith BUSBY et Erik Kooper (dir.), Courtly Literature, Culture and Context, Amsterdam/Philadelphie, John Benjamins Publishing company, 1990, p. 211-225.

HoEPPFNER, Ernest, «Les Vœux du paon et les demandes amoureuses », Archivum romanicum, 4 (1920), p. 99-104.

LABERE, Nelly, « Jeu de hasard et jeu d'adresse. Poétique des formes narratives brèves médiévales ", in Marie-Luce DeMONET (dir.), Hasard et Providence (XIV ${ }^{e}-X V I I^{e}$ siècles). Actes du XLIX Colloque International d'Études Humanistes (Tours, Université François-Rabelais, 3-9 juillet 2006), publication en ligne :

http://umr6576.cesr.univ-tours.fr/publications/HasardetProvidence

LANGLOIS, Ernest, «Le jeu du roi qui ne ment», Mélanges Chabaneau, Romanische Forschungen, t. 23 (1906), p. 163-173.

Menard, Philippe, «Le concept de loisir au Moyen Âge », in Jean-Marie ANDRE, Jacqueline DANGel, Paul DemOnt (dir.), Les Loisirs et l'héritage de la culture classique. Actes du XIII Congrès de l'Association Guillaume Budé (Dijon, 27-31 août 1993), Bruxelles, Latomus, Revue d'études latines, 1996, p. 455-469.

Piaget, Arthur, « La cour amoureuse dite de Charles VI », Romania, 20 (1891), p. 417454.

PoIrIOn, Daniel, Le Poète et le prince. L'évolution du lyrisme courtois de Guillaume de Machaut à Charles d'Orléans, Paris, PUF, 1965/ Genève, Slatkine Reprints, 1978.

Ribemont, Bernard, «Christine de Pizan et les jeux de cour (à propos des jeux à vendre) », Ludica. Annali di storia e civilità del gioco, 8 (2002), p. 49-55.

VAN DEN Neste, Évelyne, Tournois, joutes, pas d'armes dans les villes de Flandre à la fin du Moyen-âge (1300-1486), Paris, École des Chartes, 1996.

\section{Jeux théâtraux}

AubAilly, Jean-Claude, Le Monologue, le dialogue, et la sottie. Essai sur quelques genres dramatiques à la fin du Moyen Age et au début du XVI siècle, Paris, Champion, 1976.

Bordier, Jean-Pierre, Le BrIz-Orgeur, Stéphanie, PARussa, Gabriella (dir.), Le Jeu théâtral, ses marges, ses frontières, Actes de la deuxième rencontre sur l'ancien théâtre européen de 1997, Paris, Champion, « Le Savoir de Mantice », 1999.

Marie BouhaïK-Girones, Les Clercs de la Basoche et le théâtre comique (Paris, 14201550), Paris, Honoré Champion, 2007.

Cowell, Andrew, At play in the tavern : signs, coins and bodies in the Middle ages, Ann Arbor, Michigan, University of Michigan Press, 1999.

Di Stefano, Giuseppe, et Bilder, Rose M. (dir.), La Langue, le texte, le jeu. Perspectives sur le théâtre médiéval, actes du colloque international Université Mc Gill, Montréal, 2-4 octobre 1986, Le Moyen Français, 19 (1988). 
Dominguez, Véronique, La Scène et la croix. Le jeu de l'acteur dans les Passions dramatiques françaises (XIV $-X V I^{e}$ siècles), Turnhout, Brepols, "Texte, Codex \& Contexte », 2007.

DOUDET, Estelle, «Mettre en jeu, mettre en écrit: les grands rhétoriqueurs bourguignons face aux textes de théâtre », in Tania VAN HEMELRYCK et Céline VAN HoOREBEEK (dir.), L'Écrit et le manuscrit à la fin du Moyen Âge, Turnhout, Brepols, « Texte, Codex \& Contexte », 2006, p. 99-110.

DuHL, Olga Anna, «À la recherche du jeu médiéval comique: texte, théorie et spectacle virtuel », La Recherche: Bilan et perspectives, Actes du Colloque international, Université McGill, Montréal, 5-6-8 octobre 1998, Giuseppe Di STEFANO et Rose M. BILder (dir.), Le Moyen Français, 44-45 (2000), vol. 1, p. 209-221.

Koopmans, Jelle, «Esthétique du monologue : l'art de Coquillart et compagnie », in Jean-Frédéric ChEvalier (dir.), Les Mondes théâtraux autour de Guillaume Coquillart (XVe siècle), Langres, Dominique Guéniot, «Hommes et textes en Champagne », 2005, p. $27-44$.

Rousse, Michel, «L'Acteur au Moyen Âge, $\mathrm{X}^{\mathrm{e}}$-XIII ${ }^{\mathrm{e}}$ siècles : vers l'intériorisation du jeu ", La Scène et les tréteaux. Le théâtre de la farce au Moyen Âge, Orléans, Paradigme, 2004, p. 145-165.

Rousse, Michel, «L'espace scénique des farces », La Scène et les tréteaux. Le théâtre de la farce au Moyen Âge, Orléans, Paradigme, 2004, p. 92-102.

Rousse, Michel «Estormi ou l'empreinte du castelet », La Scène et les tréteaux. Le théâtre de la farce au Moyen Âge, Orléans, Paradigme, 2004, p. 274-285.

Rousse, Michel, «Propositions sur le théâtre profane avant les farces », La Scène et les tréteaux. Le théâtre de la farce au Moyen Âge, Orléans, Paradigme, 2004, p. 51-69.

VAN DEN NeSTE, Évelyne, «La fête des trente et un rois de Tournai, un jeu de rôle au $\mathrm{XIV}^{\mathrm{e}}$ siècle », Ludica. Annali di storia e civiltà del gioco, 3 (1997), p. 132-140.

Zumthor, Paul, «Poésie et théâtralité. L'exemple du Moyen Âge », Le Théâtre et la Cité : Actes du $V^{e}$ Colloque de la Société Internationale pour l'Étude du Théâtre Médiéval, Fifteenth Century Studies, 13 (1988), p. 3-12. 